\title{
Malária álgida: um diagnóstico sindrômico
}

\author{
Algid malaria: a syndromic diagnosis \\ Marcus Vinícius Guimarães de Lacerda ${ }^{1,2,3}$, Maria Paula Gomes Mourão ${ }^{1,2,3}$, \\ Pablo José Tomé dos Santos ${ }^{1}$ e Maria das Graças Costa Alecrim ${ }^{2,3}$
}

\section{RESUMO}

São relatados dois casos de pacientes com malária por Plasmodium falciparum, evoluindo com síndrome do choque. Receberam suporte hemodinâmico em unidade de terapia intensiva, sem uso de antibióticos, evoluindo com melhora. Malária álgida deve ser um diagnóstico sindrômico, de etiologia diversa (desidratação, infecção bacteriana, sangramento e/ou insuficiência adrenal).

Palavras-chaves: Plasmodium falciparum. Malária. Choque. Cuidado intensivo.

\begin{abstract}
Two patients with malaria due to Plasmodium falciparum who progressed to shock syndrome are reported. They received hemodynamic support in an intensive care unit without using antibiotics and presented improvements. Algid malaria should be a syndromic diagnosis of varying etiology (dehydration, bacterial infection, bleeding and/or adrenal insufficiency).
\end{abstract}

Key words: Plasmodium falciparum. Malaria. Shock. Intensive care.

Malária álgida é definida como presença de choque circulatório: pressão arterial (PA) sistólica inferior a $80 \mathrm{mmHg}$, na posição supina, em adultos, ou inferior a 50mmHg, em crianças, em pacientes com diagnóstico de malária ${ }^{14}$. Trata-se de uma complicação considerada rara na literatura, especialmente no Brasil, onde o número de casos de malária grave tem diminuído, em função da redução da proporção de casos de malária por Plasmodium falciparum e aumento do número de casos de malária por Plasmodium vivax ${ }^{13}$.

A seguir, são descritos dois casos de infecção por Plasmodium falciparum evoluindo com malária álgida, atendidos na Fundação de Medicina Tropical do Amazonas, uma unidade de atenção terciária, em Manaus.

\section{RELATO DOS CASOS}

Caso 1. Paciente do gênero masculino, 39 anos, evoluindo há cinco dias com síndrome febril aguda e diarréia. Recebeu o diagnóstico microscópico de malária por Plasmodium falciparum (22.854 formas assexuadas $/ \mathrm{mm}^{3}$ ). Encontrava-se afebril, desidratado, taquipnéico, oligúrico, com enchimento capilar retardado e $\mathrm{PA}=70 \mathrm{x} 40 \mathrm{mmHg}$. Exames complementares

\footnotetext{
1. Fundação de Medicina Tropical do Amazonas, Manaus, AM. 2. Centro Universitário Nilton Lins, Manaus, AM. 3. Universidade do Estado do Amazonas, Manaus, AM. Endereço para correspondência: Dr. Marcus Vinícius Guimarães de Lacerda. Gerência de Malária/FMT-AM. Av. Pedro Teixeira 25, Dom Pedro, 69040-000 Manaus, AM. Telefax: 559236560620

e-mail: marcuslacerda@uol.com.br

Recebido para publicação em 13/10/2008

Aceito em 19/01/2009
}

mostraram 3.900 leucócitos $/ \mathrm{mm}^{3}$, com 46\% de neutrófilos, hemoglobina de $9,3 \mathrm{~g} / \mathrm{dL}, 48.000$ plaquetas $/ \mathrm{mm}^{3}$ e creatinina de $1,9 \mathrm{mg} / \mathrm{dL}$. Radiografia de tórax normal. Iniciou tratamento antimalárico (artesunato intravenoso + mefloquina oral no terceiro dia) e infusão parenteral de solução cristalóide. Por apresentar piora da hipotensão $(\mathrm{PA}=50 \times 30 \mathrm{mmHg}$; pressão venosa central $=3 \mathrm{CmH}_{2} \mathrm{O}$ ), foi transferido para a unidade de terapia intensiva, sendo iniciadas aminas vasoativas. Não foi introduzida antibioticoterapia. Apenas no terceiro dia de internação apresentou normotensão arterial, com negativação da parasitemia no quarto dia após o início do tratamento antimalárico. A hemocultura não mostrou crescimento bacteriano.

Caso 2. Paciente do gênero feminino, 51 anos, evoluindo há 12 dias com síndrome febril aguda. Referia hipertensão arterial sistêmica. Recebeu o diagnóstico de malária por Plasmodium falciparum (118.140 formas assexuadas $/ \mathrm{mm}^{3}$ ). Encontrava-se afebril, desidratada, ictérica, taquipnéica, com $P A=100 \times 70 \mathrm{mmHg}$ e dor em hipocôndrio direito. Exames complementares mostraram 10.000 leucócitos $/ \mathrm{mm}^{3}$, com $65 \%$ de neutrófilos, hemoglobina de $9 \mathrm{~g} / \mathrm{dL}, 53.000$ plaquetas $/ \mathrm{mm}^{3}$, creatinina de $1,6 \mathrm{mg} / \mathrm{dL}$ e bilirrubina direta de 2,0mg/dL. Radiografia de tórax normal. Iniciou tratamento antimalárico com artesunato intravenoso, seguido de mefloquina oral no terceiro dia. Nas primeiras 12 horas de evolução hospitalar, apresentou queda dos níveis tensionais $(\mathrm{PA}=80 \mathrm{x} 40 \mathrm{mmHg})$, sudorese, pulsos finos e enchimento capilar retardado, iniciando, na unidade de terapia intensiva, infusão parenteral de solução cristalóide e aminas vasoativas. Não foi introduzida antibioticoterapia. Apenas no terceiro dia de internação,apresentou normalização da PA, recebendo alta hospitalar no quinto dia de internação, com $P A=140 \times 90 \mathrm{mmHg}$. Negativação da parasitemia no quarto dia de internação. Hemocultura e urocultura sem crescimento bacteriano. 


\section{DISCUSSÃo}

Os critérios de malária grave, definidos pela Organização Mundial da Saúde, englobam uma diversidade de complicações clínicas associadas a maior letalidade, mas que nem sempre traduzem 0 mesmo evento fisiopatogênic $0^{1}$. Assim, não há qualquer evidência de que a síndrome do choque pela malária, também conhecida como malária álgida (do latim algidus, que significa estar frio), tenha alguma associação direta com 0 seqüestro de hemácias parasitadas na microvasculatura, como acontece classicamente nos casos de malária cerebral.

A verdadeira etiologia da malária álgida ainda permanece obscura, possivelmente em função do reduzido número de casos descritos na literatura. Em 1907, Valenti sugeriu que a insuficiência adrenal era importante para a explicação das manifestações clínicas da chamada malária perniciosa. 0 clássico trabalho de Clementino Fraga, de 1918, descreveu o aumento e a congestão das glândulas supra-renais de pacientes hipotensos com malária, submetidos à autópsia7. Desde então, foram descritas lesões hemorrágicas e degenerativas nas adrenais de pacientes com choque por malária ${ }^{11}$, o que recomendava, à época, o uso de corticosteróides exógenos como parte da terapêutica ${ }^{6}$. Em 1969, estudo realizado com 25 soldados americanos com infecção não-grave por Plasmodium falciparum demonstrou que as funções adrenal e hipofisária estavam normais. A mesma observação em pacientes também com malária nãograve foi confirmada posteriormente em pacientes atendidos em Belém do Pará ${ }^{10}$. Entretanto, um único estudo realizado com nove pacientes com malária grave demonstrou insuficiência adrenal primária e secundária nessa forma mais complicada da doença ${ }^{5}$. É preciso ressaltar que as evidências de que o uso de corticóide intravenoso não promove impacto na mortalidade e de que aumenta o risco de sangramento gastrintestinal, na malária grave, se referem exclusivamente aos casos de malária cerebral ${ }^{12}$. Não existem estudos randomizados que avaliem a eficácia de corticóides em outras formas de gravidade da doença, em especial na malária álgida.

Infecções bacterianas são apontadas como possíveis responsáveis pela falência circulatória na malária álgida ${ }^{14}$. Com a realização sistemática de exames microbiológicos em pacientes graves, não é rara a descrição de casos de malária por Plasmodium falciparum complicados por sepse bacteriana ${ }^{4}$. Esses casos, entretanto, são mais freqüentes entre a população pediátrica $^{8}$ ou entre pacientes hospitalizados que tenham se submetido a procedimentos invasivos, como cateterismo vesical ${ }^{15}$. Nos dois casos relatados, pela ausência de evidências de infecção bacteriana, optou-se pela não-introdução de antibioticoterapia, e os pacientes tiveram boa evolução, apesar da recomendação de antibioticoterapia empírica de amplo espectro por alguns autores ${ }^{2}$.

Há evidências de que a hipotensão ortostática seja mais frequiente do que se descreve na literatura, constituindo uma fase precoce compensada do que classicamente é definido como malária álgida ${ }^{3}$. A desidratação observada em pacientes com malária, por diminuição da ingestão hídrica, hipertermia, sudorese, taquipnéia, vômitos e diarréia, poderia justificar de per se a hipotensão por depleção de volume, especialmente na faixa pediátrica.

Em função da diversidade de possíveis mecanismos desencadeadores da síndrome do choque na malária, sugerimos que a abordagem desta complicação seja sindrômica, com avaliação individual dos casos no momento de se decidir a terapia mais adequada. Feito o diagnóstico da síndrome do choque por malária, o primeiro passo deve ser a reposição parenteral de líquidos, baseada na estimativa individual do déficit de volume. Como existe o risco de desencadeamento de edema agudo de pulmão nos casos de hiper-hidratação, a reposição volêmica deve ser monitorada, sempre que possível, pela medida da pressão venosa central ou da pressão arterial pulmonar. Na ausência de melhora clínica, deve-se optar pela introdução de aminas vasoativas, cujo insucesso sugere o diagnóstico de insuficiência adrenal, para a qual a confirmação laboratorial é realizada pela dosagem do cortisol ou pela estimulação com corticotropina sintética. Deve-se também considerar a possibilidade de infecção bacteriana associada, sendo obrigatória a realização de exames microbiológicos. Outros possíveis complicadores da síndrome da malária álgida são: diminuição do inotropismo cardíaco, edema agudo de pulmão e sangramento abundante por coagulação intravascular disseminada ou por ruptura de hematoma subcapsular esplênico.

Cabe notar que o choque na malária não se restringe exclusivamente à infecção por Plasmodium falciparum, tendo já sido relatados casos de malária álgida por Plasmodium vivax?

0 suporte de terapia intensiva e a rápida negativação da parasitemia com o uso de esquizonticidas rápidos, tais como os derivados de artemisinina, são de fundamental importância para a recuperação dos pacientes com malária grave.

\section{REFERÊNCIAS}

1. Anstey NM, Price RN. Improving case definitions for severe malaria. PLoS Medicine 4:e267, 2007.

2. Bruneel F, Gachot B, Timsit JF, Wolff M, Bedos JP, Regnier B, Vachon F. Shock complicating severe falciparum malaria in European adults. Intensive Care Medicine 23:698-701, 1997.

3. Butler T, Weber DM. On the nature of orthostatic hypotension in acute malaria. The American Journal of Tropical Medicine and Hygiene 22:439-442, 1973.

4. Bygbjerg IC, Lanng C. Septicaemia as a complication of falciparum malaria. Transactions of the Royal Society of Tropical Medicine and Hygiene 76:705, 1982

5. Davis TM, Li TA, Tran QB, Robertson K, Dyer JR, Phan TD, Meyer D, Beaman MH, Trinh KA. The hypothalamic-pituitary-adrenocortical axis in severe falciparum malaria: effects of cytokines. Journal of Clinical Endocrinology and Metabology 82:3029-3033, 1997.

6. Flosi AZ. Contribuição para o estudo da insuficiência supra-renal palúdica - Conceito de disionia palúdica. Editora Renascença SA, São Paulo, 1944.

7. Fraga C. Notas e Lições Clínicas em Clínica Médica - Syndrome Suprarenal no Impaludismo. Livraria Catilina, Salvador, 1918.

8. Gwer S, Newton CR, Berkley JA. Over-diagnosis and co-morbidity of severe malaria in African children: a guide for clinicians. The American Journal of Tropical Medicine and Hygiene 77:6-13, 2007. 
9. Kumar S, Melzer M, Dodds P, Watson J, Ord R. P. vivax malaria complicated by shock and ARDS. Scandinavian Journal of Infectious Diseases 39:255-256, 2007.

10. Libonati RM, Mendonca BB, Maues JA, Quaresma JA, Souza JM. Some aspects of the behavior of the hypothalamus-pituitary-adrenal axis in patients with uncomplicated Plasmodium falciparum malaria: Cortisol and dehydroepiandrosterone levels. Acta Tropica 98:270-276, 2006

11. Maegraith B. Pathological processes in malaria and blackwater fever. Charles C. Thomas, Springfield, 1948.

12. McGee S, Hirschmann J. Use of corticosteroids in treating infectious diseases. Archives of Internal Medicine 168:1034-1046, 2008.
13. Ribeiro CTD, Lacerda MVG, Ferreira J0. Paludisme dû à Plasmodium vivax en Amazonie brésilienne: quelques aspects de son épidémiologie, de ses manifestations cliniques et des réactions immunitaires naturellement acquises. Bulletin de la Societé des Pathologies Exotiques et Filiales 101:243-248, 2008.

14. World Health Organization. Severe falciparum malaria. Transactions of the Royal Society of Tropical Medicine and Hygiene 94(suppl 1):S1-90, 2000.

15. World Health Organization. Guidelines for the treatment of malaria. Acessado em 26 de dezembro de 2006. Disponível em www.who.int/malaria/docs/ TreatmentGuidelines2006.pdf, 2006. 